\title{
Article
}

\author{
Doi 10.5943/sif/6/1/21
}

\section{Neofomitella guangxiensis and Sebipora aquosa newly recorded white rot polypores from India}

\section{Vinjusha N and Arun Kumar TK}

\author{
The Zamorin's Guruvayurappan College, Kozhikode, Kerala 673014, India
}

Vinjusha N, Arun Kumar TK 2021 - Neofomitella guangxiensis and Sebipora aquosa newly recorded white rot polypores from India. Studies in Fungi 6(1), 307-314, Doi 10.5943/sif/6/1/21

\begin{abstract}
As a part of the documentation of the polyporoid fungi of Kerala State, India, two interesting polypore specimens were collected. Morphological and molecular characterization revealed the identity of two species as Neofomitella guangxiensis and Sebipora aquosa, which were reported as new records to India. We present the taxonomy of the two species based on morphology and molecular phylogenetic data.
\end{abstract}

Key words - Gelatoporiaceae - Polyporaceae - Polyporales - phylogeny - wood decaying fungi

\section{Introduction}

Neofomitella Y. C. Dai, Hai J. Li \& Vlasák is a recently established genus under Polyporaceae (Polyporales), segregated from Fomitella Murrill by the presence of a distinct crust on the pileus, with cuticle extending from base to margin ( $\mathrm{Li}$ et al. 2014). The genus is characterized by annual to perennial, pileate, sessile to effused-reflexed basidiomata with glabrous to velutinate, yellowish-brown, fuscous to almost black pileus surface, often with concentric zonations or sulcations, and buff to yellowish brown or pale grey, hard corky context, and poroid hymenium with white, cream to pale buff hymenial surface, and a trimitic hyphal system with clamped generative hyphae, absence of cystidia, and oblong ellipsoid to cylindrical, colourless, thin-walled, smooth basidiospores, that are acyanophilous, and inamyloid in Melzer's reagent in which species cause white rot on angiosperm wood ( $\mathrm{Li}$ et al. 2014). Based on the molecular phylogenetic study (Li et al. 2014), Neofomitella is closely related with the genus Microporus P. Beauv. However, Microporus includes species with stipitate or infundibuliform basidiomata, and white to cream coloured context. Coriolopsis Murrill also shares some macroscopic and microscopic characters with Neofomitella, such as brown context, a trimitic hyphal system bearing generative hyphae with clamp connections, and hyaline basidiospores, and white rot type of wood decay (Gilbertson \& Ryvarden 1986, Núñez \& Ryvarden 2001, Hattori 2005). But, recent molecular phylogenetic studies ( $\mathrm{Li}$ et al. 2014, Ji et al. 2019) considered Coriolopsis as polyphyletic, as its type species (Coriolopsis occidentalis (Klotzsch) Murrill) settled in Trametes clade, which is distinct from Neofomitella. Currently, five species (N. australiensis B. K. Cui \& Xing Ji, N. fumosipora (Corner) Y.C. Dai, Hai J. Li \& Vlasák, N. guangxiensis B.K. Cui \& Xing, N. polyzonata Y. C. Dai, Hai J. Li \& Vlasák, and N. rhodophaea (Lév.) Y. C. Dai, Hai J. Li \& Vlasák) have been recognized in the genus (Index Fungorum 2021). Members of this genus have a tropical to subtropical distribution (Léveillé 1844, Ryvarden \& Johansen 1980, Corner 1989, Núñez \& Ryvarden 2001, Dai et al. 2011, Dai 2012, Li et al. 2014, Cui et al. 2019). 
Sebipora Miettinen is a genus belonging to the family Gelatoporiaceae of Polyporales, established by Miettinan (Miettinen \& Rajchenberg 2012). Major characteristics of the genus are annual, usually gelatinous, resupinate to pileate basidiomata, with a rubber like consistency, glabrous, azonate pileus that are white when fresh and cream, grey to brownish upon drying, and poroid hymenium with round to angular pores, white, homogenous context, and a monomitic hyphal system with clamped generative hyphae, either encrusted or not, and cylindrical, slightly bent, hyaline, thin-walled basidiospores that are usually guttulate, and inamyloid in Melzer's reagent. Species of Sebipora causes white rot on wood (Miettinen \& Rajchenberg 2012). The genus is closely related to species in Tyromyces P. Karst. sensu stricto, in having infrequently encrusted hyphae that are metachromatic in cresyl blue, inamyloid in Melzer's reagent, and presence of cylindrical, guttulate basidiospores. However, the former produces a dimitic hyphal system in mature fruit bodies, and their contextual hyphae possesses thick-walled, finger like projections, characters that are absent in Sebipora. Phylogenetically, Sebipora belongs to the Cinereomyces clade, which is distinct from Tyromyces sensu stricto (Miettinen \& Rajchenberg 2012). The genus consists of a single species, S. aquosa Miettinen (Index Fungorum 2021).

\section{Materials \& methods}

Fruit bodies were collected from forest areas of the Kerala region of Western Ghats in India, during the monsoon seasons. Macroscopic characters of fresh specimens were recorded. Microscopic observations were made on materials stained using aqueous solutions of $3 \%$ phloxine and $1 \%$ congo red, and mounted in $5 \%$ aqueous $\mathrm{KOH}$. Reaction of the basidiospores on treatment with Melzer's reagent and cotton blue was noted. Twenty basidiospores from each specimen were measured for obtaining the spore dimensions, range of spore quotient (Q, length/width ratio) and its mean value $\left(\mathrm{Q}_{\mathrm{m}}\right)$. All collections examined are deposited at the ZGC Herbarium, India. Current taxonomic names and systematic positions of all taxa used in this study are according to the Index Fungorum database (www.speciesfungorum.org.), accessed on 02 June 2021. Jayasiri et al. (2015) was followed to register faces of fungi numbers.

For DNA extraction from the specimens (ZGCVN689, ZGCVN775), NucleoSpin ${ }^{\circledR}$ Plant II kit (Macherey-Nagel 2014, Germany) was used. PCR amplification of ITS gene region was carried out using the primers ITS 1F and ITS 4R. Sequencing was done using BigDye Terminator v3.1 Cycle sequencing Kit (Applied Biosystems, USA). The sequencing PCR temperature profile consisted of a $1^{\text {st }}$ cycle at $96^{\circ} \mathrm{C}$ for 2 minutes, followed by 30 cycles at $96^{\circ} \mathrm{C}$ for $30 \mathrm{sec}, 50^{\circ} \mathrm{C}$ for 40 sec, and $60^{\circ} \mathrm{C}$ for 4 minutes. The newly generated ITS sequences were deposited in the GenBank database (www.ncbi.nlm.nih.gov) with accession numbers (MT365177, MT649883). Sequence similarity assessments were conducted using BLAST search in NCBI's GenBank nucleotide database (https://blast.ncbi.nlm.nih.gov/). The newly generated sequences and those taken from GenBank were aligned using MEGA X64 (Kumar et al. 2018). Sequences used in the dataset were selected from Miettinen \& Rajchenberg (2012), Cui et al. (2019) and Ji et al. (2019). Laetiporus sulphureus (Bull.) Murrill was selected as an outgroup taxon for the dataset following Cui et al. 2019. Maximum Likelihood (ML) analysis was conducted with MEGA X64 using Tamura-Nei model (Tamura \& Nei 1993). Phylogeny test was carried out using boot bootstrap method, based on 1000 bootstrap replicates. The aligned sequence data matrix was deposited in TreeBase (Submission ID: 26538, Reviewer access http://purl.org/phylo/treebase/phylows/study/TB2:S26538?X-access code $=500 \mathrm{a} 205 \mathrm{a} 67 \mathrm{e} 40 \mathrm{eb} 6 \mathrm{a} 2031591 \mathrm{ae} 0083 \mathrm{a} 7 \&$ format $=\mathrm{html}$ ).

\section{Results}

\section{Taxonomy}

Neofomitella guangxiensis B.K. Cui \& Xing Ji, in Ji, Wu, Song, Liu, Si \& Cui, Mycol. Progr. 18 (4): 599 (2019). 
Index Fungorum number: IF828730; Faces of Fungi number: FoF09464

Basidiomata annual, small to medium sized, usually in clusters, soft and coriaceous when fresh, becoming harder on drying, light in weight, effused reflexed. Pileus 26-48 mm long, 20-35 $\mathrm{mm}$ wide, 3-5 mm thick, sessile, circular to irregular, covering the host, applanate, concentric zonations absent, irregularly wrinkled, glabrous, creamish white, light brown on bruising, tissue more brownish in $\mathrm{KOH}$, margin even to slightly wavy. Hymenium poroid. Pores 4-6 per mm, round to slightly angular, oblique towards attachment region, cream, turning light brown on bruising, tubes up to $3 \mathrm{~mm}$ long, concolourous with pore surface. Context 1.5-2 $\mathrm{mm}$ thick, creamish white, homogenous. Odour not distinctive.

Hyphal system trimitic, generative hyphae with clamp-connections, skeletal hyphae thickwalled, unbranched and binding hyphae thick-walled and frequently branched. Pileipellis interwoven at base and forming an irregular cutis made of hyphae that are 2-3 $\mu \mathrm{m}$ wide, hyaline, slightly (up to $1 \mu \mathrm{m}$ ) thick to thick-walled. Pileal trama interwoven, generative hyphae $2-4 \mu \mathrm{m}$ wide, hyaline, smooth, thin to slightly (up to $1 \mu \mathrm{m}$ ) thick-walled, branched, with clampconnections. Skeletal hyphae 2-5 $\mu \mathrm{m}$ wide, hyaline, weakly dextrinoid in Melzer's reagent, thickwalled $(1 \mu \mathrm{m})$, unbranched, septations not observed. Binding hyphae 1.5-2 $\mu \mathrm{m}$ wide, hyaline, weakly dextrinoid in Melzer's reagent, thick-walled $(1 \mu \mathrm{m})$, highly branched, septations not observed. Hymenial trama interwoven, generative hyphae 2-4 $\mu \mathrm{m}$ wide, hyaline, smooth, thin to slightly (up to $1 \mu \mathrm{m}$ ) thick-walled, branched, with clamp-connections. Skeletal hyphae 2-4.5 $\mu \mathrm{m}$ wide, hyaline, weakly dextrinoid in Melzer's reagent, thick-walled, unbranched, septations not observed. Binding hyphae 1.5-2 $\mu \mathrm{m}$ wide, hyaline, weakly dextrinoid in Melzer's reagent, thickwalled $(1 \mu \mathrm{m})$, highly branched, branches short, septations not observed. Cystidia absent. Mature basidia not observed. Basidiospores 5.5-8 $\times 2-2.5 \mu \mathrm{m}, \mathrm{L}=7 \mu \mathrm{m}, \mathrm{W}=2.1 \mu \mathrm{m}, \mathrm{Q}=2.6-4, \mathrm{Q}_{\mathrm{m}}=$ 3.36, cylindrical to allantoid, hyaline, smooth, thin-walled, sometimes monoguttulate, inamyloid in Melzer's reagent, acyanophilous in cotton blue.

Material examined - India, Kerala state, Kannur district, Madayi Kavu, on dead branch of angiosperm tree, 07 July 2018, Vinjusha N, ZGCVN689.

Sebipora aquosa Miettinen, in Miettinen \& Rajchenberg, Mycol. Progr. 11 (1): 144 (2012).

Index Fungorum number: IF519513; Faces of Fungi number: FoF09465

Fig. 1

Basidiomata annual, small, in clusters, imbricate, soft, membraneous and coriaceous when fresh, becoming hard upon drying, light in weight, effused reflexed. Pileus 4-12 mm long, 6-50 $\mathrm{mm}$ wide. 2-3 mm thick, sessile, applanate to uneven, semicircular, concentric zonations absent, glabrous to hispid, white, pale brown on bruising, margin thin, undulate, lacerate, incurved on drying. Hymenium poroid. Pores 4-5 per mm, angular, absent along margin, white, pale brown on bruising, tube 1-2 $\mathrm{mm}$ long, concolourous with pore surface. Context $1 \mathrm{~mm}$ thick, white, homogenous. Odour not distinctive.

Hyphal system monomitic, generative hyphae with clamp-connections, thin to slightly (up to $1 \mu \mathrm{m})$ thick-walled, metachromatic in cresyl blue. Pileipellis a regular cutis made of hyphae that are 2-3 $4 \mathrm{~m}$ wide, hyaline, thin- to slightly (up to $1 \mu \mathrm{m}$ ) thick-walled. Pileal trama subparallel, generative hyphae 2-6 $\mu \mathrm{m}$ wide, hyaline, smooth, thin- to slightly (up to $1 \mu \mathrm{m}$ ) thick-walled, with frequent clamp-connections. Hymenial trama subparallel, hyphae 2-5 $\mu \mathrm{m}$ wide, hyaline, smooth, thin- to slightly (up to $1 \mu \mathrm{m}$ ) thick-walled, with frequent clamp-connections. Cystidia absent. Basidia 15-21 × 4-5 $\mu \mathrm{m}$, clavate, 4-sterigmate, with basal clamp-connections. Basidiospores 5-7 $\times$ 2-3 $\mu \mathrm{m}, \mathrm{L}=5.8 \mu \mathrm{m}, \mathrm{W}=2.5 \mu \mathrm{m}, \mathrm{Q}=2-3, \mathrm{Q}_{\mathrm{m}}=2.37$, cylindrical, usually curved at one end, hyaline, often monoguttulate, thin-walled, smooth, inamyloid in Melzer's reagent, acyanophilous in cotton blue.

Material examined - India, Kerala state: Palakkad district, Dhoni forest, on dead wood stump, 26 November 2018, Vinjusha N., ZGCVN775.

\section{Molecular characterization}


BLAST search using the ITS sequence of the specimen, ZGCVN689 resulted in 100\% identity with Neofomitella guangxiensis (GenBank numbers-MK192435, MK192434, MK192436). BLAST result also showed 99\% similarity with Trametes cotonea (Pat. \& Har.) Ryvarden (GenBank number- MH861271). BLAST search of the second specimen, ZGCVN775 showed $100 \%$ similarity with the sequences of Sebipora aquosa including that from the type material (GenBank numbers- KJ654615, HQ659243). BLAST search using the ITS sequence from the fruit body also resulted in $99 \%$ similarity with sequence of Ceriporiopsis subvermispora (JN116698).

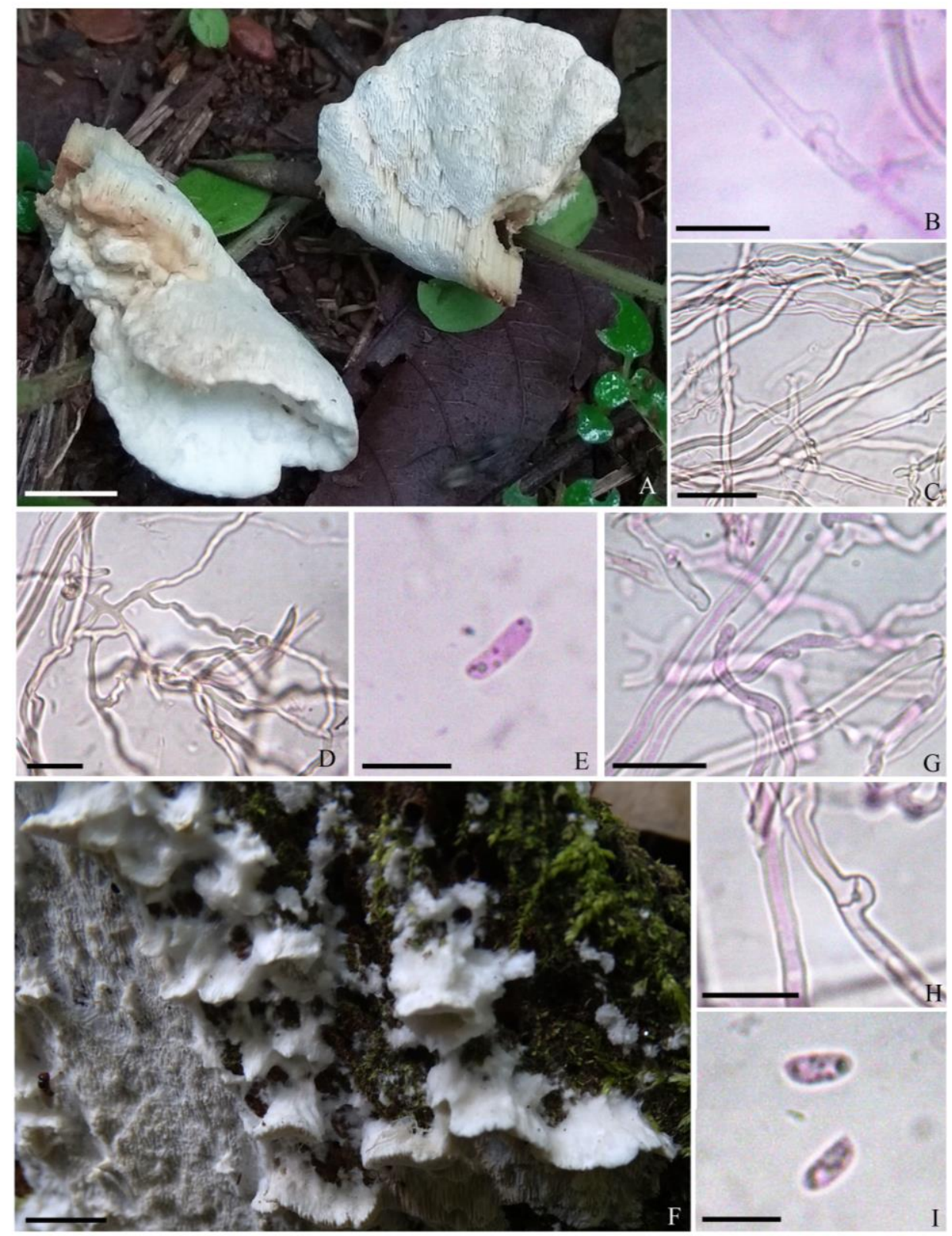

Fig. 1 - A basidiome of Neofomitella gunagxiensis. B Generative hyphae showing clamp connection. C Skeletal hyphae. D Binding hyphae. E Basidiospore. F Basidiomata of Sebipora aquosa. G Generative hyphae. H Generative hyphae showing clamp connection. I Basidiospores. Scale bars: $A=8 \mathrm{~mm}, \mathrm{~B}=10 \mu \mathrm{m}, \mathrm{C}=30 \mu \mathrm{m}, \mathrm{D}, \mathrm{E}=8 \mu \mathrm{m}, \mathrm{F}=10 \mathrm{~mm}, \mathrm{G}, \mathrm{H}=15 \mu \mathrm{m}, \mathrm{I}=7 \mu \mathrm{m}$.

The phylogenetic tree (Fig. 2) shows the placement of our collections among other related taxa of order Polyporales. Two distinct monophyletic groups of Polyporales were recognized in the tree, such as core polyporoid clade, and Cinereomyces clade. In the ITS tree, one of our collections (ZGCVN689) settled near to Neofomitella guangxiensis with $95 \%$ bootstrap support, in the core 
polyporoid clade. Similarly, the other collection (ZGCVN775) clustered along with Sebipora aquosa with $98 \%$ bootstrap support, in the Cinereomyces clade.

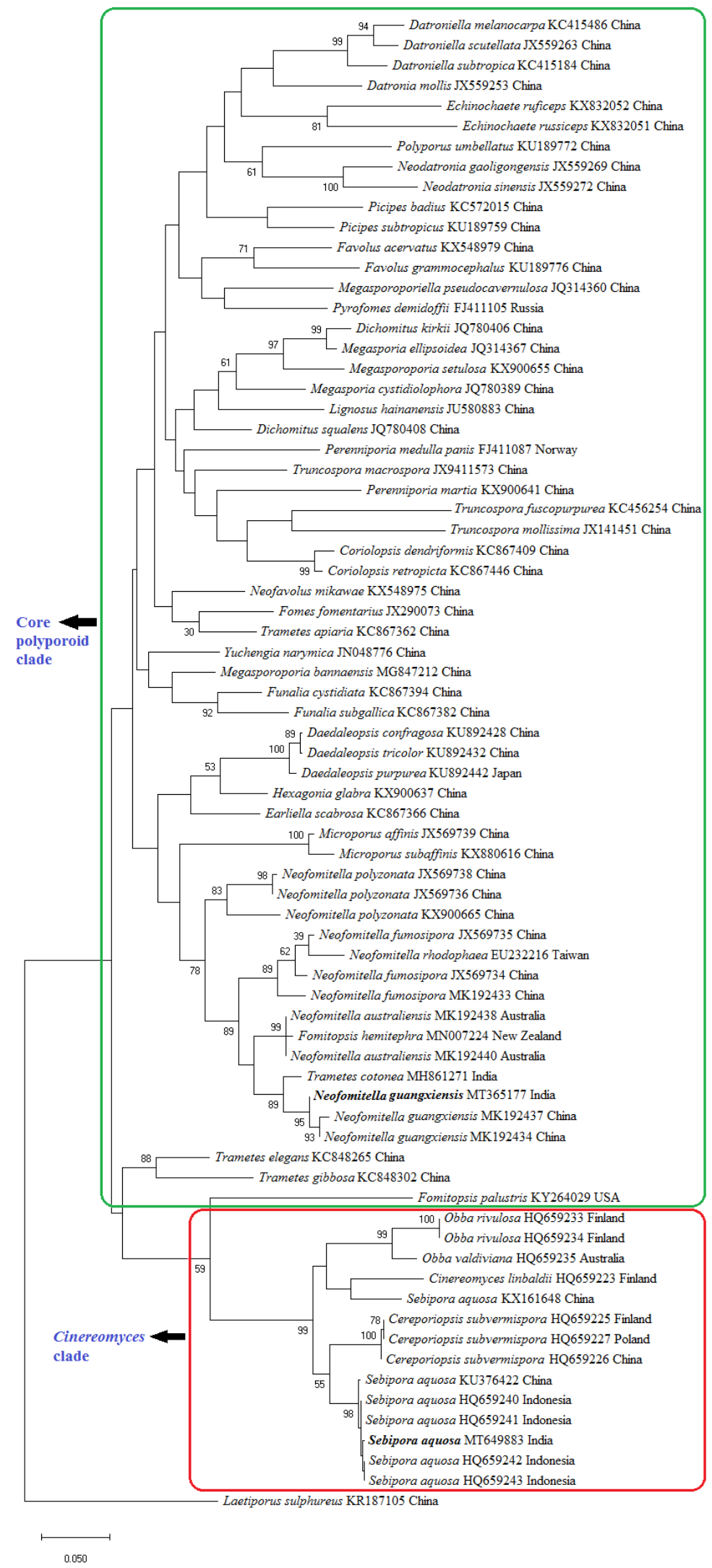

Fig. 2 - Maximum likelihood tree generated using nurITS sequence data. Values at the nodes indicate Maximum Likelihood bootstrap values. Bootstrap values above 50\% are shown. Bold 
names represent the species collected from Kerala State, India. Clades are indicated in boxes. DNA sequence accession numbers and voucher localities are given along with the taxa.

\section{Discussion}

According to Ji et al. (2019), Neofomitella guangxiensis is separated from other species in the genus by effused-reflexed to pileate basidiocarps, weakly dextrinoid skeletal and binding hyphae, and large basidiospores $(5.5-7.5 \times 1.8-2.2 \mu \mathrm{m})$. Morphological characters of the present specimen properly matched with the original description of the species by $\mathrm{Ji}$ et al. (2019), except for some variations. As per the description of Ji et al. (2019), the pileus of N. guangxiensis possesses concentric sulcations, and the hymenium produces fusoid cystidioles. However, the present collection lacks concentric zonations and sulcations on pileus, and fusoid cystidioles were not observed. Our collection resembles N. fumosipora (Corner) Y.C. Dai, Hai J. Li \& Vlasák in morphology. However, the latter species produces smaller pores (7-9 per $\mathrm{mm}$ ) and smaller basidiospores (3-4 × 1.7-2.2 $\mu \mathrm{m}$, as per the descriptions of Hattori 2005, Li et al. 2014). Neofomitella rhodophaea also shows some similarities with the present specimen. However according to Ji et al. (2019), N. rhodophaea have smaller pores (7-9 per $\mathrm{mm}$ ) and oblong ellipsoid basidiospores. Neofomitella australiensis and N. polyzonata are distinguished from our collection by the smaller basidiospores $(3.8-4.9 \times 1.8-2.3 \mu \mathrm{m}$ in $N$. australiensis; 3.9-5 $\times 1.9-2.1 \mu \mathrm{m}$ in $N$. polyzonata, according to descriptions of $\mathrm{Ji}$ et al. 2019, $\mathrm{Li}$ et al. 2014 respectively). In addition, pileus surface of $N$. polyzonata are velutinate, and buff-yellow to reddish brown.

In the BLAST search, ITS sequence of the present collection showed $99 \%$ similarity with a strain of Trametes cotonea (Pat. \& Har.) Ryvarden, reported from India. However, the latter can be morphologically separated from our collection by larger basidiospores $(7-11 \times 2.5-3.5 \mu \mathrm{m}$, Ryvarden \& Johansen 1980). In the phylogenetic tree (Fig. 2), T. cotonea settled in a separate lineage from our collection. Phylogenetic analysis clearly reveals the identity of our first collection (ZGCVN689) as N. guangxiensis. All of the original collections of N. guangxiensis (Ji et al. 2019), were reported from fallen branches of angiosperm trees. Similarly, collection of the species from Kerala was also obtained from a fallen dead branch. So far, $N$. guangxiensis has been recorded only from its type locality, Guangxi Auto. Reg., Shangsi County, China. The present study forms the first report of the species outside its type locality.

Sebipora aquosa has been described from Indonesia, New Guinea and Yunnan Province, China (Miettinen \& Rajchenberg 2012, Glen et al. 2014, Zhao et al. 2017). As per the descriptions of Miettinen \& Rajchenberg (2012) and Zhao et al. (2017), basidiocarps of S. aquosa are usually gelatinous, however, the present collection lacks this character since the specimen was collected in slightly dried form. Morphologically, present specimen resembles Ceriporiopsis subvermispora (Pilát) Niemelä. According to the taxonomic descriptions (Lowe 1966, Niemelä 1985, Ryvarden \& Gilbertson 1993), C. subvermispora always produces resupinate fruit bodies. However, the present collection produces effused reflexed basidiomata. Microscopically, C. subvermispora produces allantoid basidiospores with a width of 1-1.2 $\mu \mathrm{m}$, whereas our collection possessed cylindrical basidiospores, which are 2-3 $\mu \mathrm{m}$ wide. In addition, $C$. subvermispora has eguttulate spores, while those of the present collection were mostly monoguttulate. C. subvermispora produces hyphae that swell in KOH (Miettinen \& Rajchenberg 2012), but hyphal swellings were absent in the present collection. Moreover, $C$ subvermispora is typically a North American species according to Miettinen \& Rajchenberg (2012). Molecular phylogenetic analysis (Fig. 2) also clearly distinguishes $C$. subvermispora from our collection. Thus, morphological characterization and molecular phylogeny identifies our second collection (ZGCVN775) as S. aquosa.

According to the research of Miettinen \& Rajchenberg (2012), substrates of S. aquosa were always a fallen angiosperm tree trunk. Zhao et al. (2017) also recorded the species from fallen angiosperm trunk. But Glen et al. (2014) reported the species on root of Acacia mangium. From India, an ITS sequence of $S$. aquosa has been deposited in the GenBank database (GenBank number: JQ746682), however the data remains unpublished and the reliability of the sequence identified as "S. aquosa" is also doubted. In India, S. aquosa has been isolated from corneal 
scrapings of keratitis patients (Nithya \& Bhaskar 2013). However the paper (Nithya \& Bhaskar 2013) does not provide a systematic account of the species, and neither the voucher material nor its molecular data has been deposited or made available. Hence, the present study forms the first systematic record of $S$. aquosa from India based on a voucher deposit and molecular sequence.

\section{Acknowledgements}

Vinjusha N. acknowledges support from the Kerala State Council for Science, Technology and Environment (KSCSTE) in the form of a research fellowship. The authors thank the Chief Conservator of Forests \& Chief Wildlife Warden, Kerala, for permission for fieldwork in the forest areas of Kerala.

\section{References}

Corner EJH. 1989 - Ad Polyporaceas VI: the genus Trametes. Beihefte zur Nova Hedwigia 97: 191-197.

Cui BK, Li HJ, Ji X, Zhou JL et al. 2019 - Species diversity, taxonomy and phylogeny of Polyporaceae (Basidiomycota) in China. Fungal Diversity 97: 137-392. Doi 10.1007/s13225019-00427-4

Dai YC. 2012 - Polypore diversity in China with an annotated checklist of Chinese polypores. Mycoscience 53: 49-80. Doi 10.1007/s10267-011-0134-3

Dai YC, Cui BK, Yuan HS, He SH et al. 2011 - Wood-inhabiting fungi in southern China 4. Polypores from Hainan Province. Annales Botanici Fennici 48: 219-231. Doi 10.5735/085.048.0302

Gilbertson RL, Ryvarden L. 1986 - North American Polypores. Vol. 1. Fungiflora, Oslo, Norway, 433p.

Glen M, Yuskianti V, Puspitasari D, Francis A et al. 2014 - Identification of basidiomycete fungi in Indonesian hardwood plantations by DNA barcoding. Forest Pathology 44: 496-508. Doi $10.1111 /$ efp. 12146

Hattori T. 2005 - Diversity of wood-inhabiting polypores in temperate forest with different vegetation types in Japan. Fungal Diversity 18: 73-88.

Index Fungorum. 2021 - www.indexfungorum.org (Accessed on June 2, 2021)

Jayasiri SC, Hyde KD, Ariyawansa HA, Bhat J et al. 2015 - The Faces of Fungi database: fungal names linked with morphology, phylogeny and human impacts. Fungal Diversity 74 (1): 3-18. Doi 10.1007/s13225-015-0351-8

Ji W, Wu DM, Song CG, Liu S et al. 2019 - Two new Neofomitella species (Polyporaceae, Basidiomycota) based on morphological and molecular evidence. Mycological Progress 18: 593-602. Doi 10.1007/s11557-019-01472-8

Kumar S, Stecher G, Li M, Knyaz C, Tamura K. 2018 - MEGA X: Molecular Evolutionary Genetics Analysis across computing platforms. Molecular Biology and Evolution 35: 1547-1549. Doi 10.1093/molbev/msy096

Léveillé JH. 1844 - Champignons exotiques. Annales des Sciences Naturelles Botanique. 2: $167-221$.

Li HJ, Li XC, Vlasák J, Dai YC. 2014 - Neofomitella polyzonata gen. et sp. nov., and $N$. fumosipora and N. rhodophaea transferred from Fomitella. Mycotaxon 129: 7-20. Doi $10.5248 / 129.7$

Lowe JL. 1966 - Polyporaceae of North America. The genus Poria. New York State Univ. Coll. Forestry 90: 1-183.

Macherey-Nagel. 2014 - NucleoSpin ${ }^{\circledR}$ Plant II: Genomic DNA from Plant User manual, June 2014/Rev.03.

Miettinen O, Rajchenberg M. 2012 - Obba and Sebipora, new polypore genera related to Cinereomyces and Gelatoporia (Polyporales, Basidiomycota). Mycological Progress 11: 131e147. Doi 1007/s11557-010-0736-8 
Niemelä T. 1985 - On Fennoscandian polypors 9. Gelatoporia nov. gen. and Tyromyces canadensis, plus notes on Skeletocutis and Antrodia. Karstenia 25: 21-40.

Nithya V, Bhaskar A. 2013 - 16S and 18S rRNA gene sequencing of atypical clinical isolated microorganisms identified in keratitis patients. Clinical Research 2013, 6p.

Núñez M, Ryvarden L. 2001 - East Asian polypores. Synopsis Fungorum. 14: 170-522.

Ryvarden L, Gilbertson RL. 1993 - European Polypores, part 2. Synopsis Fungorum 7: 394-743.

Ryvarden L, Johansen I. 1980 - A preliminary polypore flora of East Africa. Fungiflora, Oslo, 630p.

Tamura K, Nei M. 1993 - Estimation of the number of nucleotide substitutions in the control region of mitochondrial DNA in humans and chimpanzees. Molecular Biology and Evolution 10: $512-526$.

Zhao CL, Liu SH, Ren GJ, Ji XH, He S. 2017 - Three species of wood-decaying fungi in Polyporales new to China. Mycotaxon 132: 29-42. Doi 10.5248/132.29 